\title{
COMUNICACÕES
}

\section{Aplicações preventivas e erradicantes de fungicidas no controle da ferrugem asiática da soja}

\author{
Guilherme Rossato Augusti ${ }^{1}$, Bruno Giacomini Sari ${ }^{1}$, Ivan Francisco Dressler da Costa ${ }^{1}$, Joelton dos Santos \\ Rodrigues $^{1}$, Renato Carnellosso Guerra ${ }^{1}$
}

${ }^{1}$ Departamento de Defesa Fitossanitária, Universidade Federal de Santa Maria (UFSM), Av. Roraima, 1000, Cidade Universitária, 97105-900, Santa Maria, RS, Brasil.

Autor para correspondência: Guilherme Rossato Augusti (graugusti@yahoo.com.br).

Data de chegada: 22/05/2014. Aceito para publicação em: 15/08/2014.

$10.1590 / 0100-5405 / 2006$

A utilização de fungicidas é a principal ferramenta de controle da ferrugem asiática da soja (Phakopsora pachyrhizi Sydow \& Sydow). Atualmente a mistura de trizóis + estrobilurinas é amplamente utilizada no controle da doença. Porém uma nova molécula fungicida do grupo das carboxamidas (fluxapiroxade) foi lançada recentemente como alternativa no controle da ferrugem. Este fato demanda informações a respeito do seu efeito sobre o patógeno, de modo que se possa posicionar de forma correta a sua aplicação. Na safra 2011/2012 foi realizado um experimento em casa-de-vegetação, no município de Santa Maria/RS, com o objetivo de testar o efeito protetor e a eficiência no controle da ferrugem asiática da soja do fungicida piraclostrobina + epoxiconazol + fluxapiroxade $\left(64,8+40+40\right.$ g i.a. ha $\left.{ }^{-1}\right)$ em diferentes momentos de aplicação (pré e pós inoculação da ferrugem) comparando a um fungicida padrão composto pela mistura azoxistrobina + ciproconazol $\left(60+24\right.$ g i.a. ha $\left.{ }^{-1}\right)$. Para isso, inoculou-se plantas da cultivar de soja BMX 'Potência' RR no estádio R5.2 com uma suspensão contendo $1 \times 10^{5}$ esporos $\mathrm{ml}^{-1}$ de $P$. pachyrhizi. Os fungicidas foram aplicados nos estádios fenológicos R1, R5.2 (48 horas antes da inoculação), 10 dias após a inoculação (DAI) e 17 DAI, utilizando-se um volume de aplicação de $150 \mathrm{~L} \mathrm{ha}^{-1}$. O delineamento utilizado foi o blocos ao acaso, em esquema fatorial 3 (fungicidas + testemunha) x 4 (momentos de aplicação), com quatro repetições, sendo cada parcela composta por quatro plantas de soja. Dois dias após a inoculação, avaliações diárias foram realizadas no sexto, oitavo e décimo trifólio de todas as plantas da parcela para determinar o número de dias para o aparecimento da primeira pústula e, assim, determinar o período de proteção dos fungicidas. Após a visualização da primeira pústula, cinco avaliações semanais foram realizadas nos mesmos trifólios para determinar a severidade da ferrugem, utilizando-se uma escala diagramática (Godoy,C.V. et al. Diagrammatic scale for assessment of soybean rust severity. Fitopatologia Brasileira, v.31, n.1, 2006). Com esses dados calculou-se a área abaixo da curva de progresso da doença (AACPD) (Campbell, C.L.; Madden, L.V. Introduction to plant disease epidemiology. New York: Wiley, 1990. 560 p.). Os dados foram submetidos a análise da variância e as médias comparadas pelo teste de Scott-Knott $(p<0,05)$. A utilização do fungicida com mistura tripla não resultou em um maior período de proteção quando comparado ao fungicida padrão em nenhum estádio de aplicação. O maior período de proteção dos fungicidas foi observado no décimo trifólio e em aplicações realizadas próximas a inoculação da ferrugem. Além da proximidade entre a pulverização e a inoculação, a maior absorção de fungicidas e a menor susceptibilidade de tecidos mais jovens à ferrugem estão relacionadas com o atraso no aparecimento dos sintomas. Analisando-se a AACPD conclui-se que, de maneira geral, as aplicações preventivas dos fungicidas são mais eficientes no controle da ferrugem em relação a aplicações erradicantes. Porém, o controle da doença não diferiu entre os fungicidas nas aplicações preventivas em todos os trifólios. Nas aplicações erradicantes, houve uma maior eficiência do fungicida piraclostrobina + epoxiconazol + fluxapiroxade quando comparado ao fungicida padrão apenas no décimo trifólio, resultado da maior absorção do fungicida em folíolos superiores e do aumento do número de sítios de ação sobre o patógeno. Portanto, a utilização de fungicidas com mistura tripla pode ser uma importante ferramenta em aplicações erradicantes, podendo ser posicionado em aplicações mais tardias, protegendo o tecido sadio, principalmente, no terço superior das plantas, que possui folhas mais jovens. 
Tabela 1. Dias $\left(\mathrm{n}^{\circ}\right)$ para o aparecimento da primeira pústula e severidade da ferrugem asiática da soja em diferentes trifólios submetidos a diferentes momentos de aplicação e fungicidas

\begin{tabular}{|c|c|c|c|c|c|}
\hline \multicolumn{6}{|c|}{ Dias $\left(\mathrm{n}^{\circ}\right)$ para o aparecimento da primeira pústula nos estádios fenológicos } \\
\hline \multirow[b]{3}{*}{ Azox. + Cipr.** } & $\mathrm{R} 1 * * *$ & R5.1 & $10 \mathrm{DAI}$ & 17 DAI & \\
\hline & \multicolumn{4}{|c|}{ 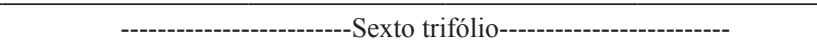 } & \multirow[t]{2}{*}{ Média (trifólios) } \\
\hline & $16,25 \mathrm{aA}^{*}$ & $17,00 \mathrm{aA}$ & $4,62 \mathrm{aB}$ & $4,75 \mathrm{aB}$ & \\
\hline Pira. + Epox. + Flux. & $17,00 \mathrm{aA}$ & $17,75 \mathrm{aA}$ & $4,00 \mathrm{aB}$ & $4,25 \mathrm{aB}$ & $8,55 \mathrm{c}$ \\
\hline \multirow[t]{2}{*}{ Testemunha } & $4,25 \mathrm{bA}$ & $4,25 \mathrm{bA}$ & $4,25 \mathrm{aA}$ & $4,25 \mathrm{aA}$ & \\
\hline & \multicolumn{4}{|c|}{------------------------Oitavo trifólio------------------------ } & \\
\hline Azox. + Cipr. & $18,25 \mathrm{aA}$ & $20,00 \mathrm{aA}$ & $9,00 \mathrm{aB}$ & $10,00 \mathrm{aB}$ & \\
\hline Pira. + Epox. + Flux. & $18,50 \mathrm{aA}$ & $20,25 \mathrm{aA}$ & $8,50 \mathrm{aB}$ & $9,00 \mathrm{aB}$ & $12,12 \mathrm{~b}$ \\
\hline \multirow[t]{2}{*}{ Testemunha } & $8,00 \mathrm{bA}$ & $8,00 \mathrm{bA}$ & $8,00 \mathrm{aA}$ & $8,00 \mathrm{aA}$ & \\
\hline & \multicolumn{4}{|c|}{-------'Décimo trifólio----------------- } & \\
\hline Azox. + Cipr. & $22,50 \mathrm{aB}$ & $24,75 \mathrm{aA}$ & $10,75 \mathrm{aC}$ & $9,75 \mathrm{aC}$ & \\
\hline Pira. + Epox. + Flux. & $22,50 \mathrm{aB}$ & $24,75 \mathrm{aA}$ & $8,75 \mathrm{bC}$ & $9,00 \mathrm{aC}$ & $14,06 \mathrm{a}$ \\
\hline Testemunha & $9,00 \mathrm{bA}$ & $9,00 \mathrm{bA}$ & $9,00 \mathrm{bA}$ & $9,00 \mathrm{aA}$ & \\
\hline Média (estádios) & $15,14 \mathrm{~B}$ & $16,19 \mathrm{~A}$ & $7,43 \mathrm{C}$ & $7,55 \mathrm{C}$ & \\
\hline \multirow[t]{3}{*}{$\mathrm{CV}(\%)$} & \multicolumn{4}{|c|}{11,34} & \\
\hline & \multicolumn{4}{|c|}{ Área abaixo da curva de progresso da doença (AACPD) } & \\
\hline & $\mathrm{R} 1 * * *$ & R5.1 & $10 \mathrm{DAI}$ & $17 \mathrm{DAI}$ & \\
\hline & \multicolumn{4}{|c|}{ - } & Média (trifólios) \\
\hline Azox. + Cipr. & $66,59 \mathrm{bC}$ & $45,65 \mathrm{bC}$ & $112,33 \mathrm{bB}$ & $174,78 \mathrm{bA}$ & \\
\hline Pira. + Epox. + Flux. & $59,32 \mathrm{bC}$ & $49,21 \mathrm{bC}$ & $98,55 \mathrm{bB}$ & $138,11 \mathrm{bA}$ & $241,71 \mathrm{a}$ \\
\hline \multirow[t]{2}{*}{ Testemunha } & $539,00 \mathrm{aA}$ & $539,00 \mathrm{aA}$ & $539,00 \mathrm{aA}$ & $539,00 \mathrm{aA}$ & \\
\hline & \multicolumn{4}{|c|}{-------------------------Oitavo trifólio------------------------ } & \\
\hline Azox. + Cipr. & $33,80 \mathrm{bB}$ & $31,77 \mathrm{bB}$ & $45,63 \mathrm{bB}$ & $85,76 \mathrm{bA}$ & \\
\hline Pira. + Epox. + Flux. & $47,18 \mathrm{bB}$ & $31,15 \mathrm{bB}$ & $47,66 \mathrm{bB}$ & $93,43 \mathrm{bA}$ & $106,71 \mathrm{~b}$ \\
\hline \multirow[t]{2}{*}{ Testemunha } & $215,79 \mathrm{aA}$ & $215,79 \mathrm{aA}$ & $215,79 \mathrm{aA}$ & $215,79 \mathrm{aA}$ & \\
\hline & \multicolumn{4}{|c|}{------------------------Décimo trifólio------------------------ } & \\
\hline Azox. + Cipr. & $21,22 \mathrm{bB}$ & $7,18 \mathrm{bC}$ & $26,18 \mathrm{bB}$ & $42,25 \mathrm{bA}$ & \\
\hline Pira. + Epox. + Flux. & $26,64 \mathrm{bA}$ & $8,33 \mathrm{bC}$ & $16,32 \mathrm{cB}$ & $31,59 \mathrm{cA}$ & $49,51 \mathrm{c}$ \\
\hline Testemunha & $103,62 \mathrm{aA}$ & $103,62 \mathrm{aA}$ & $103,62 \mathrm{aA}$ & $103,62 \mathrm{aA}$ & \\
\hline Média (estádios) & $123,68 \mathrm{C}$ & $114,74 \mathrm{C}$ & $133,90 \mathrm{~B}$ & $148,26 \mathrm{~A}$ & \\
\hline $\mathrm{CV}(\%)$ & & & & & \\
\hline
\end{tabular}

*Médias seguidas pela mesma letra maiúscula nas linhas e minúscula nas colunas não diferem estatisticamente entre si pelo teste de Scott-Knott a 5\% de probabilidade de erro.** Azox. + Cipr.: azoxistrobina + ciproconazol; Pira. + Epox. + Flux.: piraclostrobina + epoxiconazol + fluxapiroxade ***R1: Uma flor aberta em qualquer nó do caule; R5.1: Grãos perceptíveis ao tato;10 DAI: aplicação 10 dias após a inoculação; 17 DAI: aplicação 17 dias após a inoculação. 